Review Article

\title{
Prevalence of Fluoroquinolone-Resistant Campylobacter Species in Iran: A Systematic Review and Meta-Analysis
}

\author{
Farzad Khademi ${ }^{1}$ and Amirhossein Sahebkar (D) $^{2,3,4}$ \\ ${ }^{1}$ Department of Microbiology, School of Medicine, Ardabil University of Medical Sciences, Ardabil, Iran \\ ${ }^{2}$ Neurogenic Inflammation Research Center, Mashhad University of Medical Sciences, Mashhad, Iran \\ ${ }^{3}$ Biotechnology Research Center, Pharmaceutical Technology Institute, Mashhad University of Medical Sciences, Mashhad, Iran \\ ${ }^{4}$ Halal Research Center of IRI, FDA, Tehran, Iran \\ Correspondence should be addressed to Amirhossein Sahebkar; amir_saheb2000@yahoo.com
}

Received 17 July 2020; Accepted 14 October 2020; Published 30 October 2020

Academic Editor: Clemencia Chaves Lopez

Copyright ( $) 2020$ Farzad Khademi and Amirhossein Sahebkar. This is an open access article distributed under the Creative Commons Attribution License, which permits unrestricted use, distribution, and reproduction in any medium, provided the original work is properly cited.

\begin{abstract}
Background. Campylobacter species are one of the main causes of bacterial food poisoning worldwide. Recently, WHO reported that the emergence of fluoroquinolone-resistant Campylobacter species is becoming a public health issue around the world. The aim of the present systematic review and meta-analysis was to evaluate the prevalence of the antimicrobial susceptibility patterns of Campylobacter species, especially fluoroquinolone-resistant strains isolated from human and animal origins in Iran. Methods. Using related keywords and without date and language limitations, a comprehensive literature search was conducted in PubMed, Scopus, ISI Web of Knowledge, Google Scholar, and SID to identify relevant studies on the prevalence of the antimicrobial susceptibility patterns of Campylobacter species in Iran. Results. A total of 34 reports (9 in Persian and 25 in English) were selected based on inclusion and exclusion criteria. Disk diffusion, E-test, and agar dilution were common methods used for antimicrobial susceptibility testing. The antibiotic resistance profiles of Campylobacter species against fluoroquinolones were as follows: $53.6 \%$, $41.8 \%$, and $0 \%$ to ciprofloxacin for C. jejuni, C. coli, and C. lari, respectively, $24.3 \%$ and $25.1 \%$ to enrofloxacin for C. jejuni and C. coli, respectively, $59.6 \%$ and $49.2 \%$ to nalidixic acid for C. jejuni and C. coli, respectively, and $87.3 \%$ and $64.7 \%$ to ofloxacin for C. jejuni and C. coli, respectively. Conclusion. Our findings revealed a high prevalence of fluoroquinolone-resistant Campylobacter species in Iran. This calls for the use of more effective antibiotics with low resistance rates including aminoglycosides, chloramphenicol, and imipenem.
\end{abstract}

\section{Introduction}

The genus Campylobacter includes small, motile, and curved Gram-negative bacteria [1-3]. These rod-shaped bacteria are thermophilic, $30^{\circ} \mathrm{C}$ to $46^{\circ} \mathrm{C}$, and microaerophilic, $5 \% \mathrm{O}_{2}$, and belong to the family Campylobacteraceae [4]. Campylobacter is a zoonotic pathogen that is colonized in the intestinal tract of domestic and wild animals and birds and can infect human through consumption of contaminated water, different foods such as raw or uncooked meat, unpasteurized milk, and contact with infected animals or (rarely) human $[4,5]$. Poultry, cattle, sheep, pigs, birds, dogs, and cats are common reservoir hosts for human infections [2]. This foodborne bacterial pathogen is the major cause of bacterial gastroenteritis and septicemia in humans in both developing and developed countries [1, 2]. In developed countries, Campylobacter bacteria are the most important causative agents for gastrointestinal infection [6]. It is estimated that between 400 and 500 million individuals become infected with Campylobacter species in the world annually $[4,5]$. The most common species associated with bacterial gastroenteritis in human are Campylobacter jejuni and Campylobacter coli as well as Campylobacter fetus associated with systemic infections [2, 4]. Additionally, in some cases, these enteric pathogens are associated with two immune-related late complications, i.e., Guillain-Barré syndrome and reactive arthritis $[1,2]$. The severity of Campylobacter infections 
varies from a mild and self-limiting illness to severe infections [5]. For the treatment of self-limiting intestinal infections, the replacement of fluids and electrolytes is enough, while severe extraintestinal Campylobacter infections such as septicemia, endocarditis, and septic thrombophlebitis should be treated with appropriate antibiotics $[2,7]$. Macrolides, including erythromycin and azithromycin, and fluoroquinolones are considered as the drugs of choice for infected patients $[2,4,5]$. Alternative treatments are tetracyclines and gentamicin $[2,4,5]$. Additionally, Campylobacter strains are susceptible to amoxicillin/clavulanic acid, imipenem, aminoglycosides, chloramphenicol, and clindamycin [2]. However, in recent years, antimicrobial resistance of Campylobacter species has been increased in both developing and developed countries and is becoming a global problem [8]. It is noteworthy that resistance to penicillins, cephalosporins, and sulfonamides has emerged [2]. On the other hand, in February 2017, the World Health Organization (WHO) announced that fluoroquinolone-resistant Campylobacter species are growing globally, calling for a priority to find effective antibiotics [9]. Therefore, the aim of the present systematic review and meta-analysis was to evaluate the antimicrobial susceptibility patterns of Campylobacter species, especially fluoroquinolone-resistant strains, isolated from human and animal origins in Iran.

\section{Methods}

2.1. Literature Search and Selection Criteria. We started at 1 August 2018 for a comprehensive literature search in international search engines including PubMed (https://www. ncbi.nlm.nih.gov), Scopus (https://www.scopus.com), ISI Web of Knowledge (https://www.isiwebofknowledge.com), Google Scholar (http://scholar.google.com), and Scientific Information Database (SID) (http://www.sid.ir), a national database, on each report about the prevalence of the antimicrobial susceptibility patterns of Campylobacter species in Iran. There was no date and language limitation for searching, and related keywords used were antibiotic resistance, Campylobacter species (C. jejuni, C. coli, and C. lari), and Iran. A number of missed studies were obtained by reviewing the list of references and searching for journals. The meta-analysis was performed step by step based on the PRISMA recommendations [10].

Inclusion or exclusion criteria for assessing eligibility in the study were all types of Persian- and English-language articles which had enough data on the prevalence of the resistance patterns of campylobacters, in species level, to different antibiotics in Iran. Review articles, case reports, abstracts of articles, and duplicates were excluded. Articles evaluating the resistance patterns of campylobacters only at the genus level or the resistance genes and those studies with unclear results were excluded.

2.2. Data Extraction of Articles. After completely reviewing all included studies by two authors, needed information was extracted and placed in Tables 1-3 based on organism species type. The quality of data was evaluated based on the Newcastle-Ottawa scale adapted for cross-sectional studies (data has not been shown). The checklist of items was based on three criteria including selection (representativeness of the sample, sample size, nonrespondents, and ascertainment of the exposure) (maximum 5 stars), comparability (comparability of outcome groups) (maximum 2 stars), and outcome (assessment of the outcome and statistical test) (maximum 3 stars).

Data obtained from eligible studies include publishing year, location of the study, number of strains, origin of samples, methods used for antimicrobial susceptibility testing, and antibiotic resistance profiles of C. jejuni, C. coli, and C. lari.

2.3. Meta-Analysis. The data for the quantitative data synthesis were transferred to the Comprehensive Meta-Analysis (CMA) software (Biostat, Englewood, NJ). Resistance rates of C. jejuni, C. coli, and C. lari were calculated for each antibiotic as a percentage and expressed as $95 \%$ confidence intervals (95\% CIs). $I^{2}$ statistic was used to evaluate the existed heterogeneity, and considering the percent of inconsistency among studies, pooling of data was performed using fixed-or random-effects models. The assessment of publication bias was done using funnel plots.

\section{Results}

3.1. Characteristics of Included Studies. As shown in Figure 1, a total of 1299 articles were obtained from five databases (PubMed, Scopus, ISI Web of Knowledge, Google Scholar, and SID). According to the presented inclusion or exclusion criteria in Figure 1, 1249 articles were removed and the eligibility of 50 remained articles was evaluated. Among them, 16 studies did not meet inclusion criteria because of reporting the resistance patterns of campylobacters only in the genus level or had inadequate information, while 34 articles ( 9 in Persian and 25 in English) had complete data and were included in our meta-analysis.

The characteristics of the 34 included studies are summarized in Tables $1-3$. The main data was extracted from 3 studies from Ahvaz [11-13], 2 studies from Hamadan $[14,15], 4$ studies from Isfahan [16-19], 1 study from Kerman [20], 1 study from Kurdistan [21], 2 studies from Mashhad [22, 23], 1 study from Mazandaran and Golestan [24], 1 study from Rafsanjan [25], 5 studies from Shahrekord [13, 18, 26-28], 2 studies from Semnan [29, 30], 4 studies from Shiraz [31-34], 8 studies from Tehran [35-42], 2 studies from Tonekabon [34, 43], 1 study from Yazd [19], and 1 study from Zahedan [44]. Disk diffusion, E-test, and agar dilution were the most common methods used to evaluate antibiotic-resistant Campylobacter species in Iran (Tables 1-3). Additionally, the most common Campylobacter species for which their antibiotic resistance has been evaluated were C. jejuni, C. coli, and C. lari. The origins of Campylobacter species were human and animal fecal samples as well as food samples with animal origin including milk, dairy products, and animal meats like poultry, cattle, 


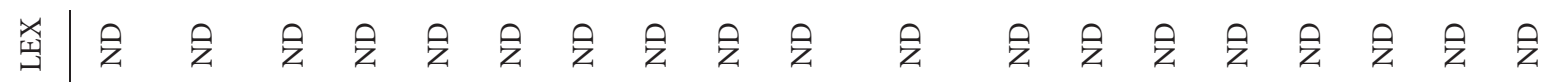

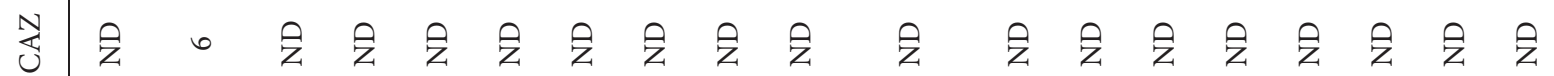

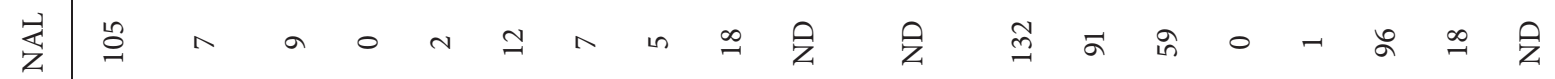

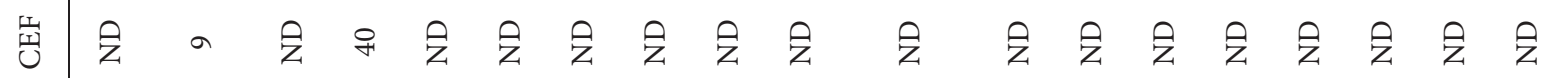

善会会会会门立会会会会。主会会会会会会会

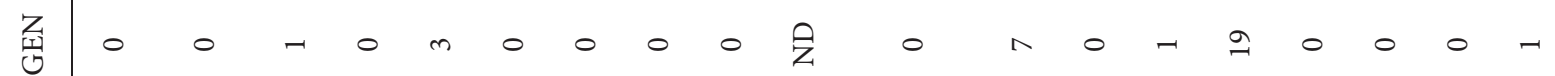

总会会会会会会会会会会会会会会会会会会会

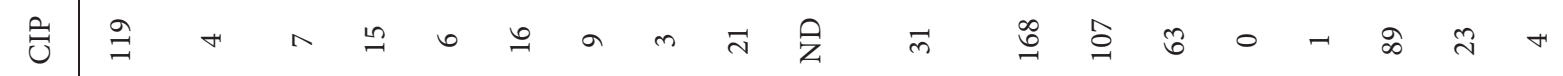

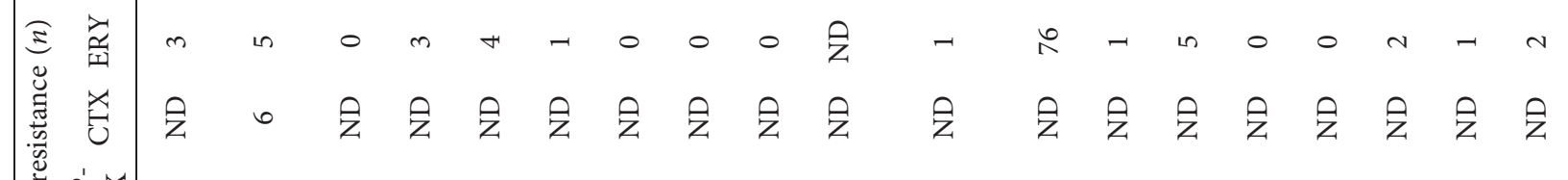

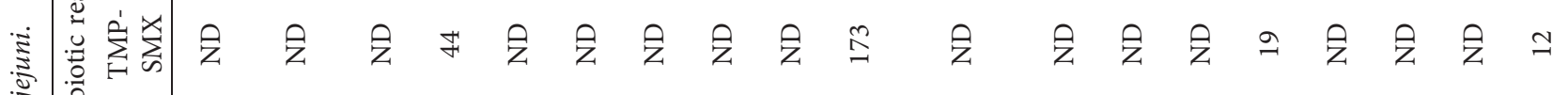

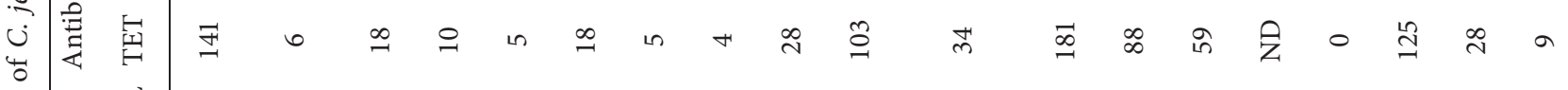

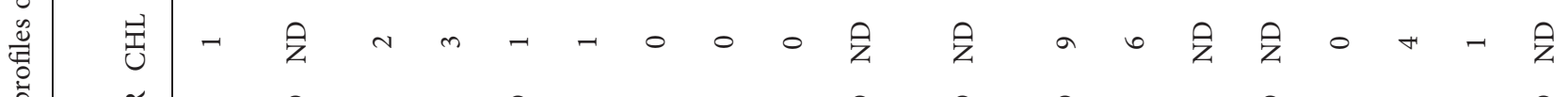

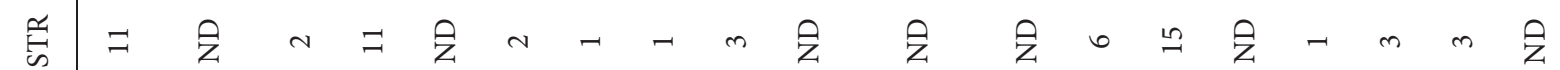

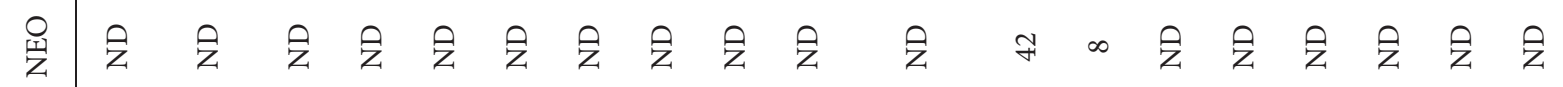

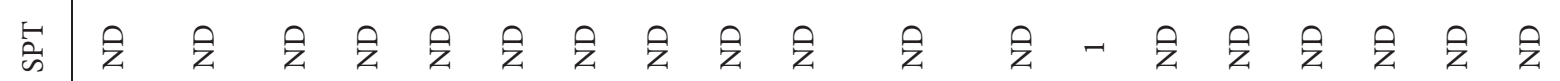

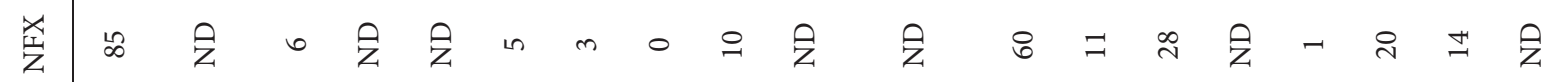

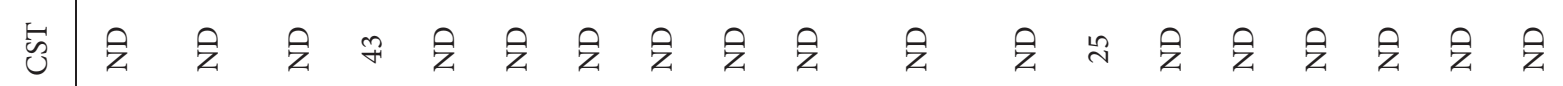

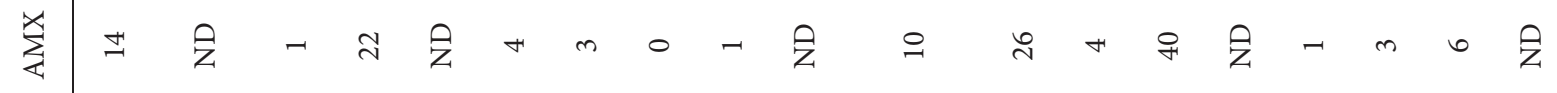

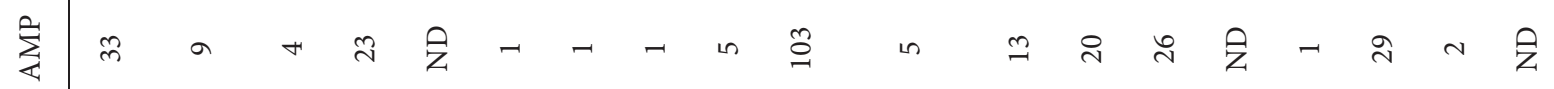

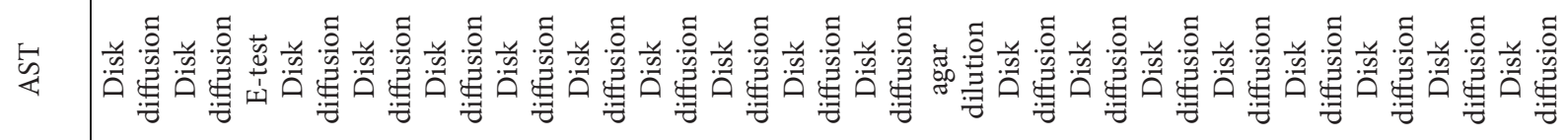

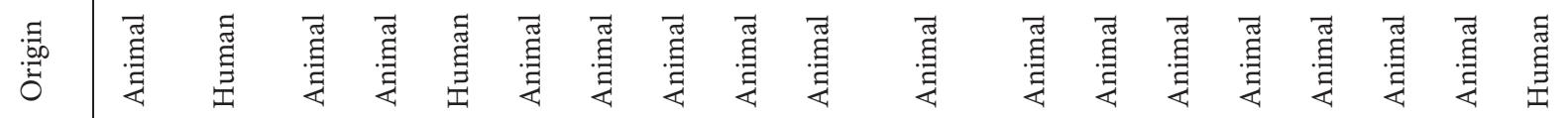

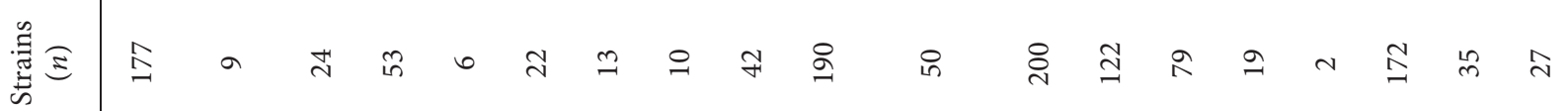

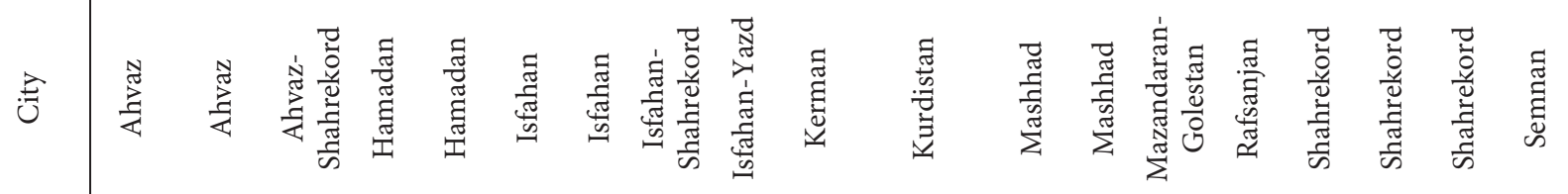

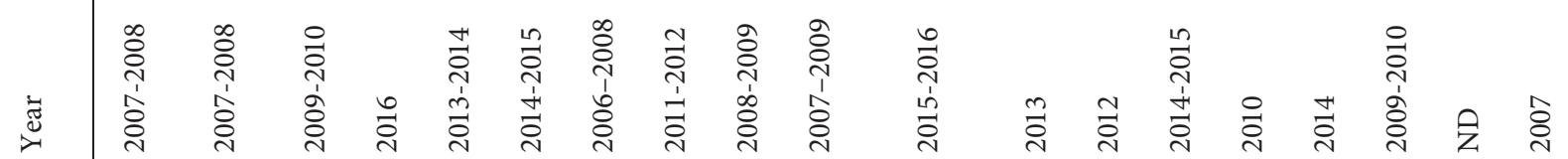




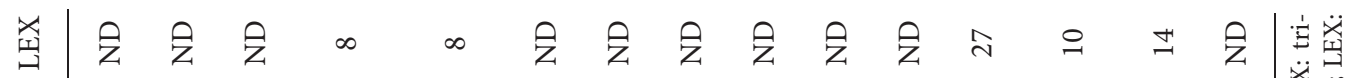

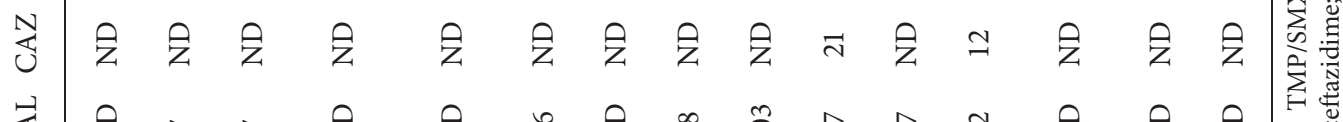

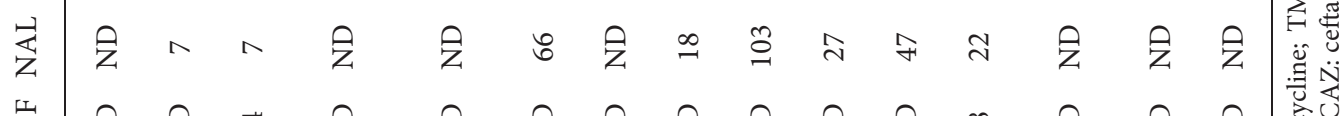

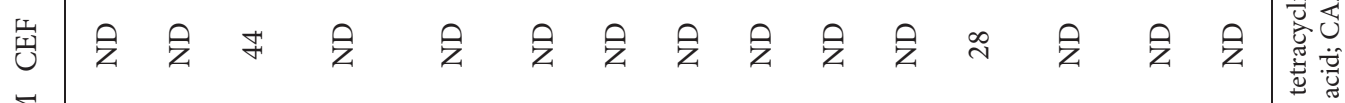

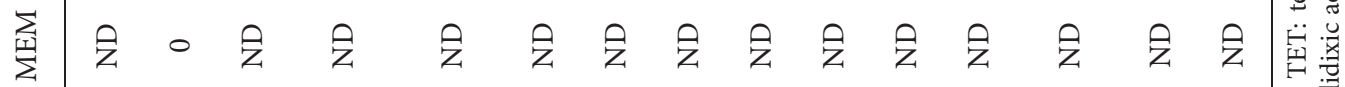

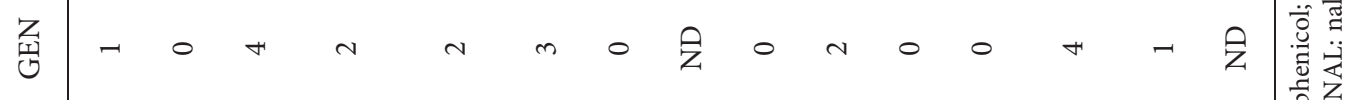

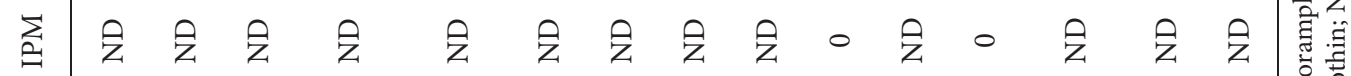

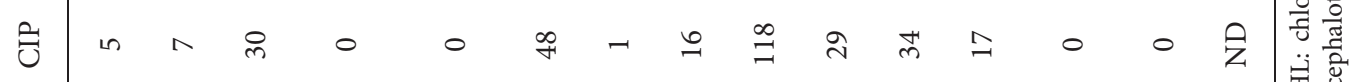

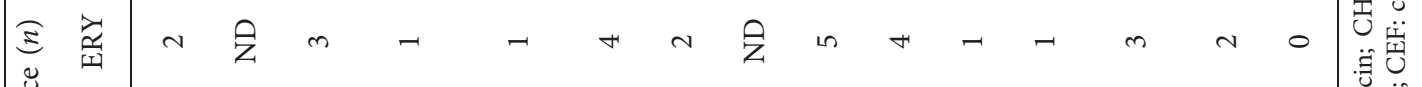

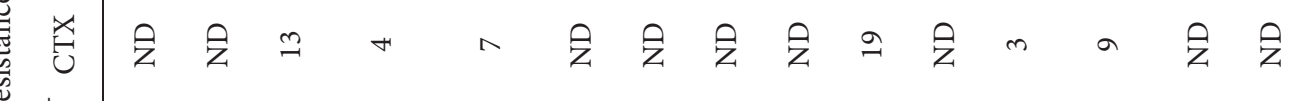

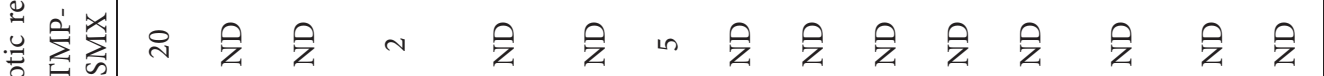

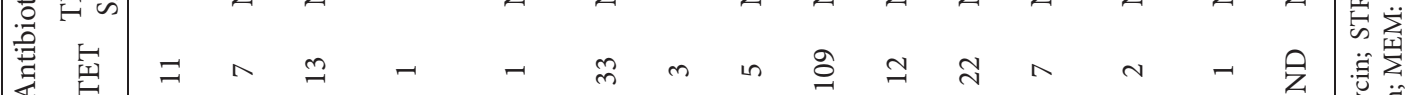

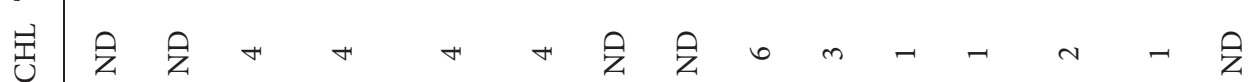

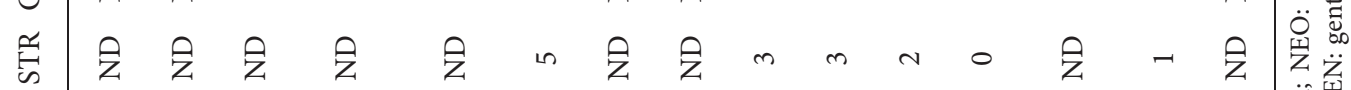

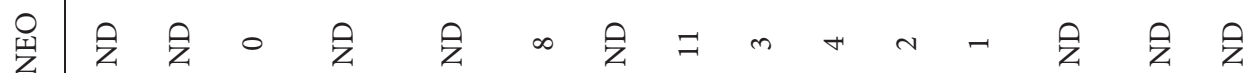

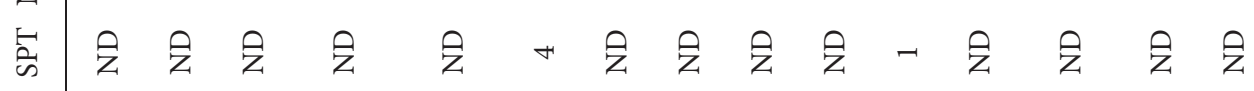

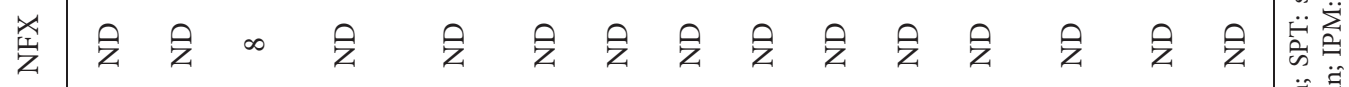

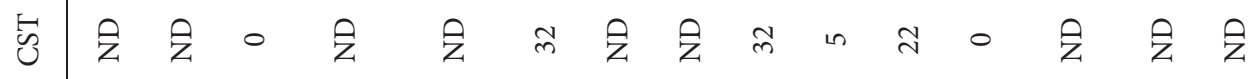

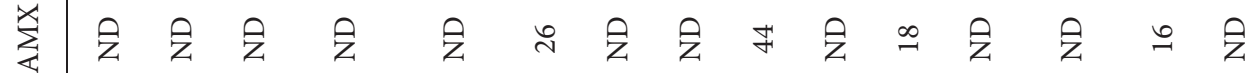

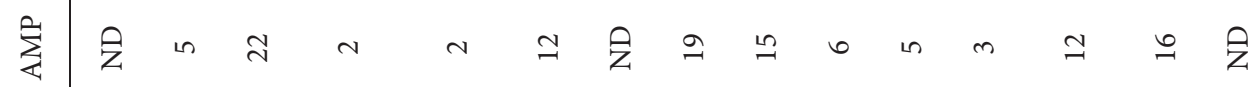

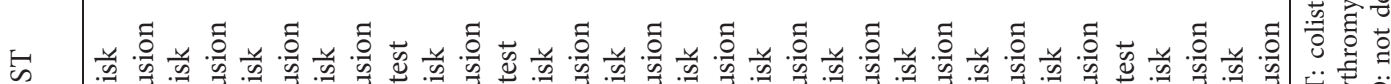

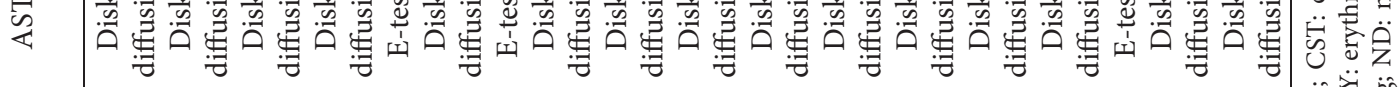

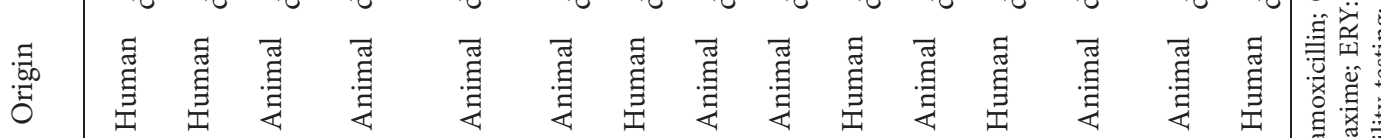

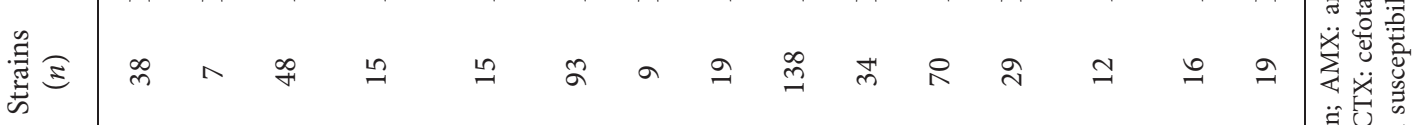

8
0

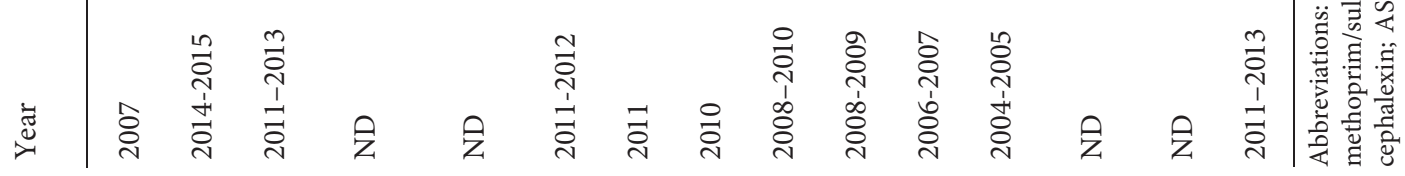


兽会会会会会会会会会会会会会会会会会主

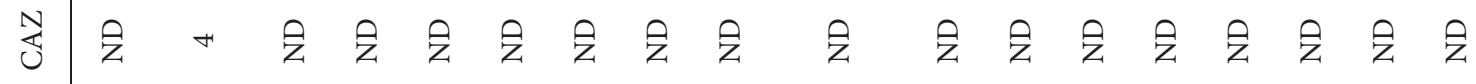

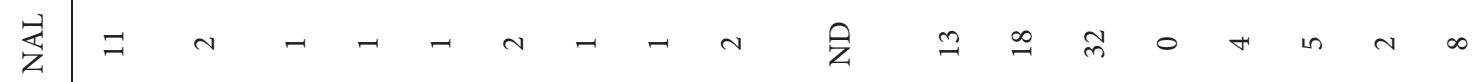

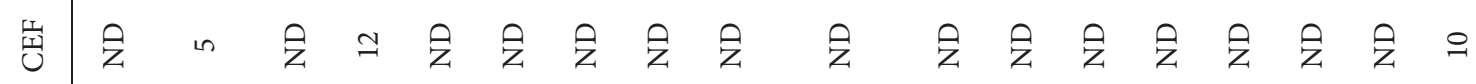

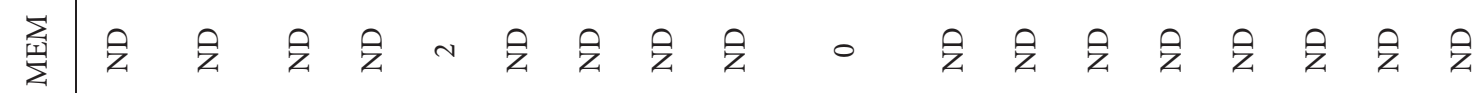

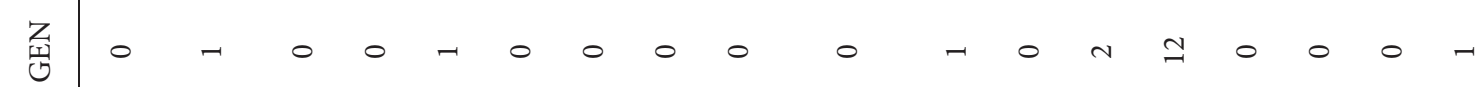
冚会会会会会会会会会会会会会会会会会会

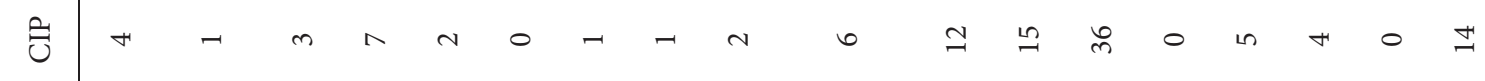
ह

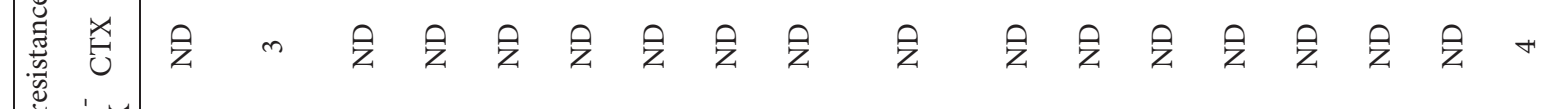

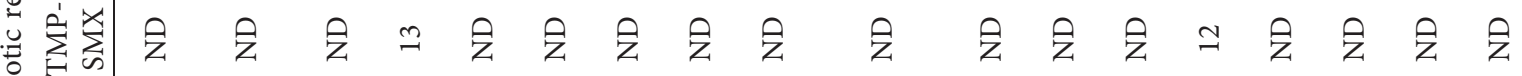

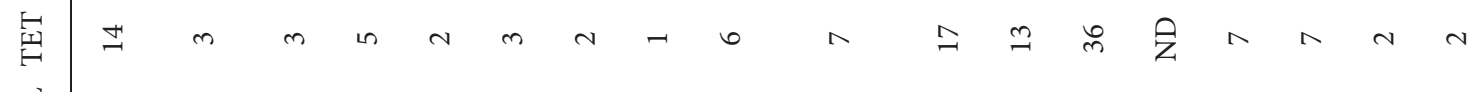

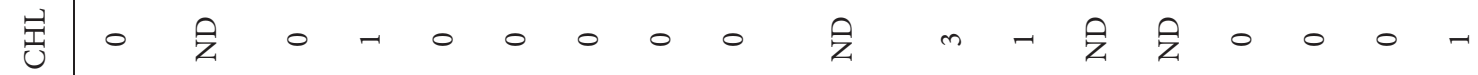

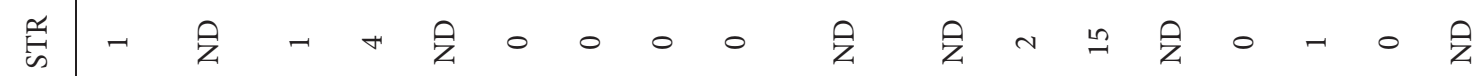

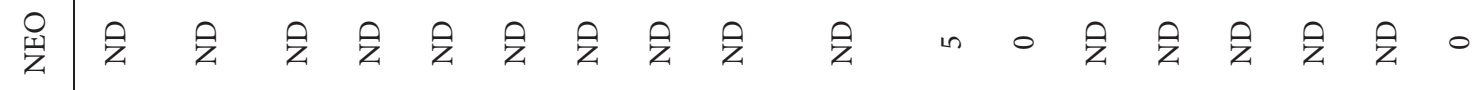

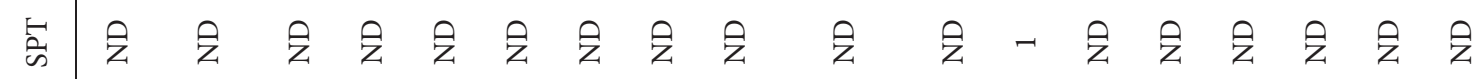

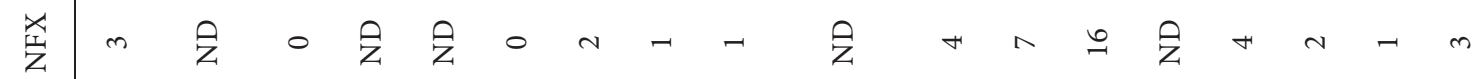

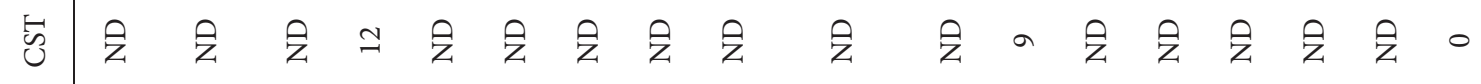

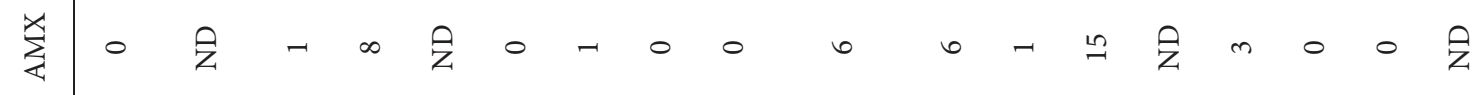

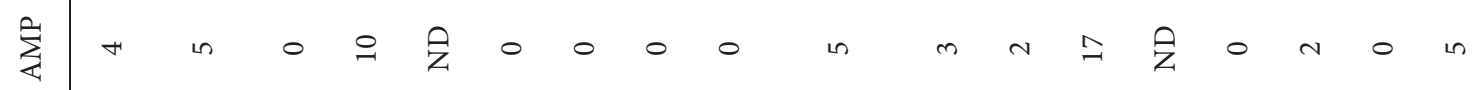

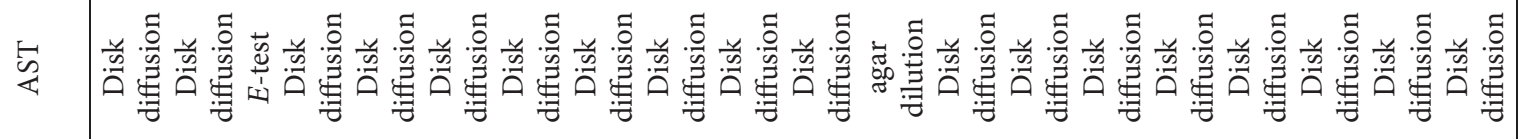

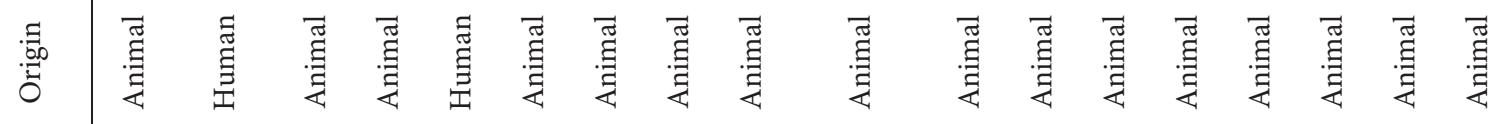

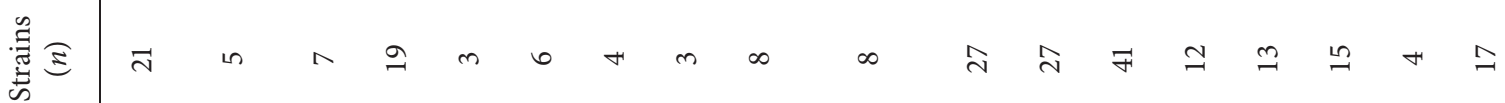

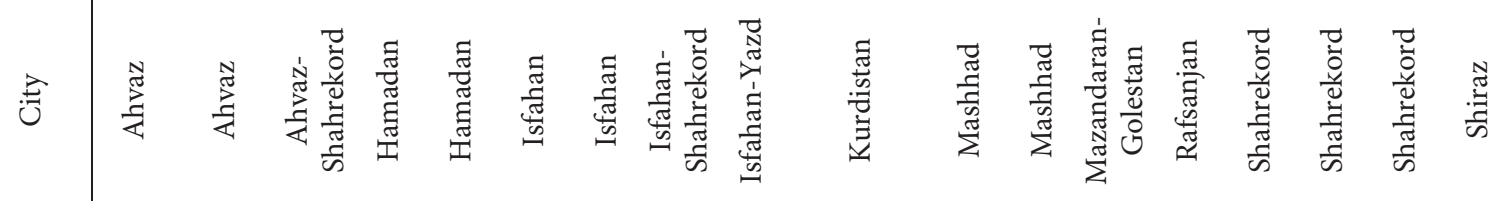

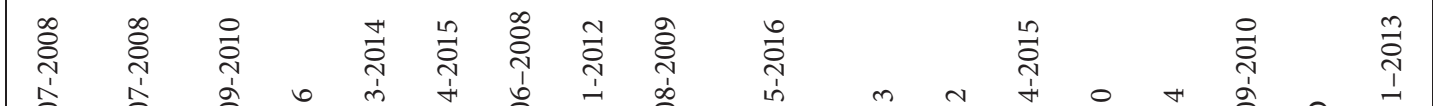
䒕 


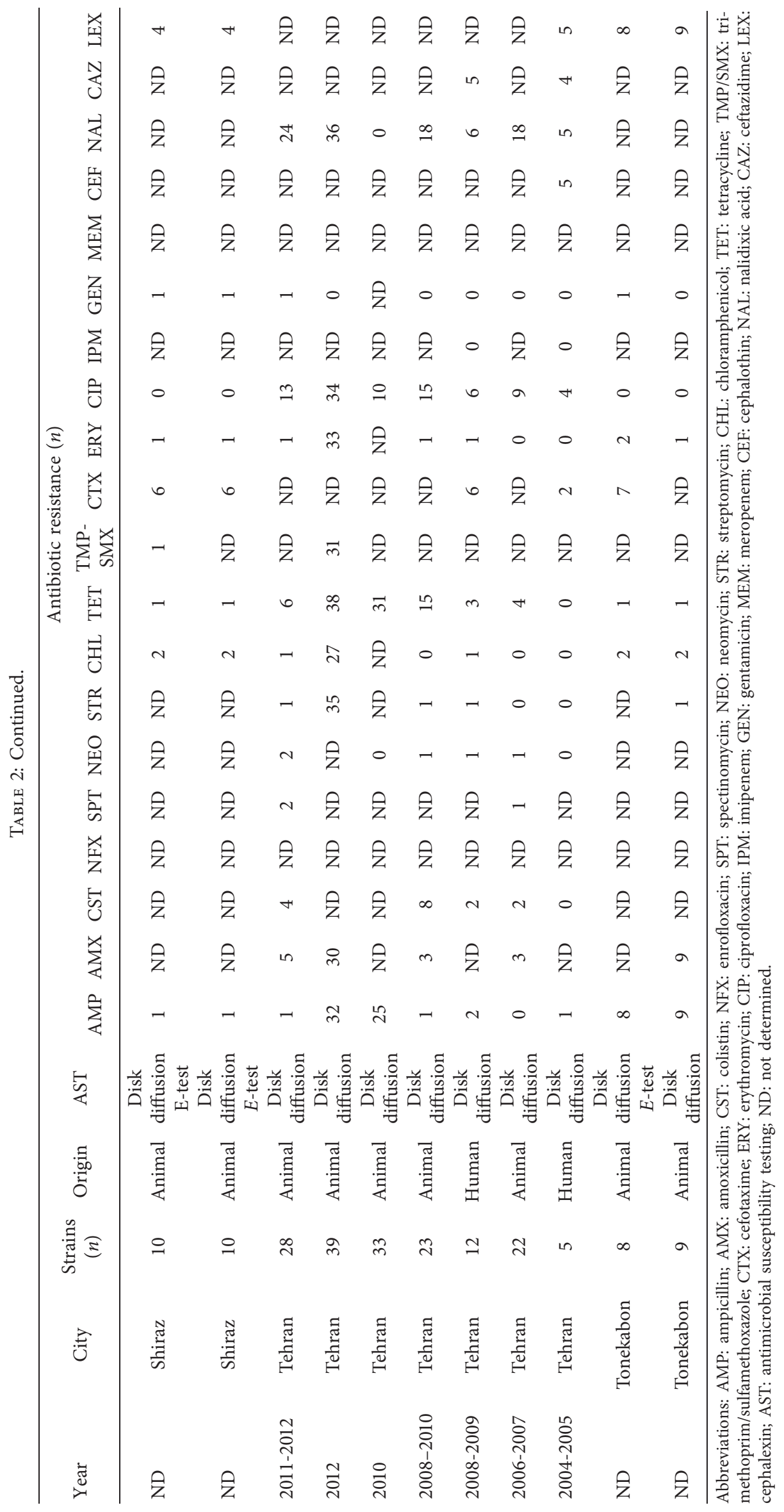




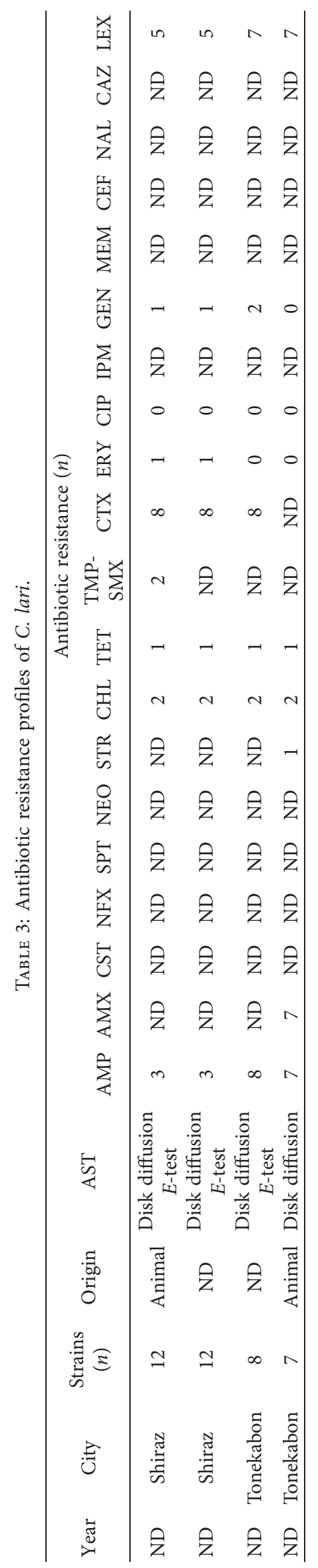




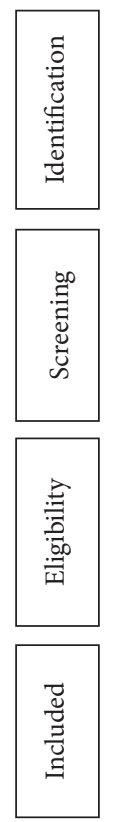

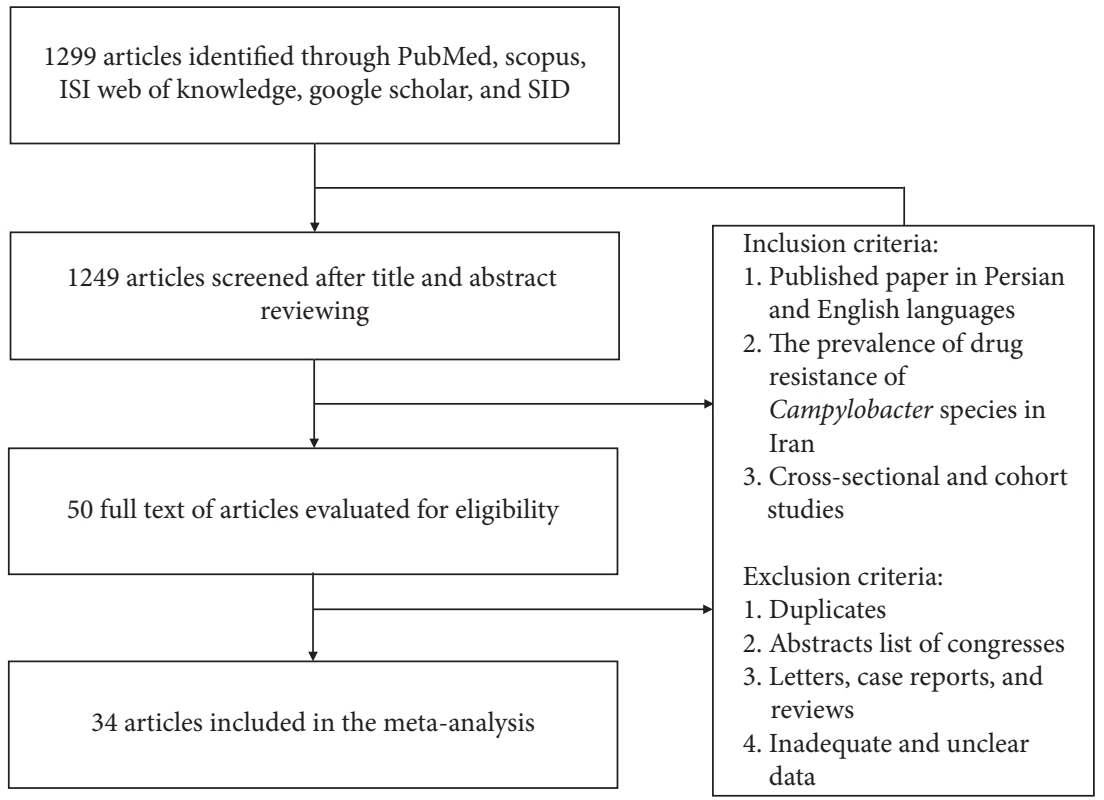

Figure 1: A summary of the study selection processes. sheep, camels, beef, water buffalo, ducks, and geese. A random-effects model was used for pooling data on the prevalence of antibiotic resistance of Campylobacter species due to the presence of high heterogeneity $\left(I^{2}>25 \%\right)$. There was some evidence of publication bias (Figures 2 and 3 ).

3.2. Characteristics of C. jejuni Antibiotic Resistance. In our presented meta-analysis, a total of 34 studies determined the prevalence of C. jejuni antibiotic resistance (Table 1). Antimicrobial resistance patterns of C. jejuni in Iran were as follows: $22.8 \%$ (95\% CI: $15.9-31.6)$ to ampicillin, $17.7 \%$ (95\% CI: $11.4-26.5)$ to amoxicillin, $25.8 \%$ (95\% CI: $14.5-41.7)$ to colistin, $24.3 \%$ (95\% CI: $16.8-33.7$ ) to enrofloxacin, $2.3 \%$ (95\% CI: $0.8-6.4$ ) to spectinomycin, $8.6 \%$ (95\% CI: $3.9-17.7$ ) to neomycin, $7.1 \%$ (95\% CI: $4.7-10.7$ ) to streptomycin, $6 \%$ (95\% CI: $4.1-8.6)$ to chloramphenicol, 50.7\% (95\% CI: 41.1-60.4) to tetracycline, $66.9 \%$ (95\% CI: $40.5-85.8)$ to trimethoprim/sulfamethoxazole, $41.2 \%$ (95\% CI: $25.1-59.5$ ) to cefotaxime, $6.4 \%$ (95\% CI: $3.6-11.1)$ to erythromycin, 53.6\% (95\% CI: 43.9-62.9) to ciprofloxacin (Figure 4), $0 \%$ to imipenem, 4.5\% (95\% CI: 2.5-7.7) to gentamicin, 9.5\% (95\% CI: $0.6-65.5)$ to meropenem, $89.4 \%$ (95\% CI: $73.8-96.2)$ to cephalothin, $59.6 \%$ (95\% CI: $52.1-66.7)$ to nalidixic acid, $54.6 \%$ (95\% CI: 38.9-69.4) to ceftazidime and 76.5\% (95\% CI: 54.5-89.8) to cephalexin. Additionally, other antibiotic resistance patterns were as follows: clindamycin $4(66.6 \%)$, tylosin $15(31.2 \%)$, oxacillin $9(100 \%)$, amikacin $4(5.1 \%)$, azithromycin $0(0 \%)$, ceftriaxone $9(56.2 \%)$, amoxi-clave 16 (100\%), penicillin 16 (100\%), vancomycin 16 (100\%), tobramycin $4(25 \%)$, ofloxacin $55(87.3 \%)$, and carbenicillin $25(39.6 \%)$.

3.3. Characteristics of C. coli Antibiotic Resistance. The characteristics of the 29 studies that determined the prevalence of $C$. coli antibiotic resistance are summarized in
Table 2. The prevalence of resistance of $C$. coli to different antibiotics was as follows: $24.5 \%$ (95\% CI: $14.5-38.4)$ to ampicillin, 23.5\% (95\% CI: 13.7-37.2) to amoxicillin, $23.1 \%$ (95\% CI: $12.1-39.5)$ to colistin, $25.1 \%$ (95\% CI: $19.2-32.1)$ to enrofloxacin, 5.4\% (95\% CI: 2-13.5) to spectinomycin, $8.3 \%$ (95\% CI: 4.7-14.1) to neomycin, $11.6 \%$ (95\% CI: $5.4-23.3$ ) to streptomycin, $9.6 \%$ (95\% CI: $4.9-17.8)$ to chloramphenicol, $47.7 \%$ (95\% CI: 35.6-60.1) to tetracycline, $67.2 \%$ (95\% CI: $33.6-89.3)$ to trimethoprim/sulfamethoxazole, $51.5 \%(95 \%$ CI: $35.8-66.9)$ to cefotaxime, $13 \%$ (95\% CI: 6.9-23) to erythromycin, $41.8 \%$ (95\% CI: $31.4-53.1$ ) to ciprofloxacin (Figure 5), 0\% to imipenem, 6.8\% (95\% CI: 4.3-10.5) to gentamicin, $27.2 \%$ (95\% CI: $1.2-92.2$ ) to meropenem, $65.5 \%$ (95\% CI: $50.1-78.2)$ to cephalothin, $49.2 \%$ (95\% CI: $36.6-61.9)$ to nalidixic acid, $62.2 \%$ (95\% CI: $31.8-85.2)$ to ceftazidime, and 73\% (95\% CI: 38.6-92.1) to cephalexin. Additionally, other antibiotic resistance patterns were as follows: clindamycin $2(66.6 \%)$, tylosin $2(11.7 \%)$, oxacillin 5 (100\%), amikacin $3(7.3 \%)$, ceftriaxone 9 (100\%), amoxiclave $9(100 \%)$, penicillin $9(100 \%)$, vancomycin $9(100 \%)$, tobramycin $0(0 \%)$, ofloxacin $11(64.7 \%)$, and carbenicillin 7 (41.1\%).

3.4. Characteristics ofC. lari Antibiotic Resistance. A total of 4 studies investigating the prevalence of C. lari antibiotic resistance were included in the meta-analysis (Table 3). Antimicrobial resistance patterns of C. lari in Iran were as follows: 60\% (95\% CI: 19-90.5) to ampicillin, 93.7\% (95\% CI: 46.1-99.6) to amoxicillin, $14.3 \%$ (95\% CI: $2-58.1)$ to streptomycin, $20.9 \%$ (95\% CI: $10.8-36.7$ ) to chloramphenicol, $10.5 \%$ (95\% CI: 4-24.9) to tetracycline, $16.7 \%$ (95\% CI: 4.2-47.7) to trimethoprim/sulfamethoxazole, $70.4 \%(95 \%$ CI: $51.3-84.3)$ to cefotaxime, $7.4 \%$ (95\% CI: $2.4-20.6)$ to erythromycin, $0 \%$ to ciprofloxacin, $12.7 \%$ (95\% CI: $5.1-28.5$ ) to gentamicin, and $63.2 \%$ (95\% CI: $32.7-85.9)$ to cephalexin. 


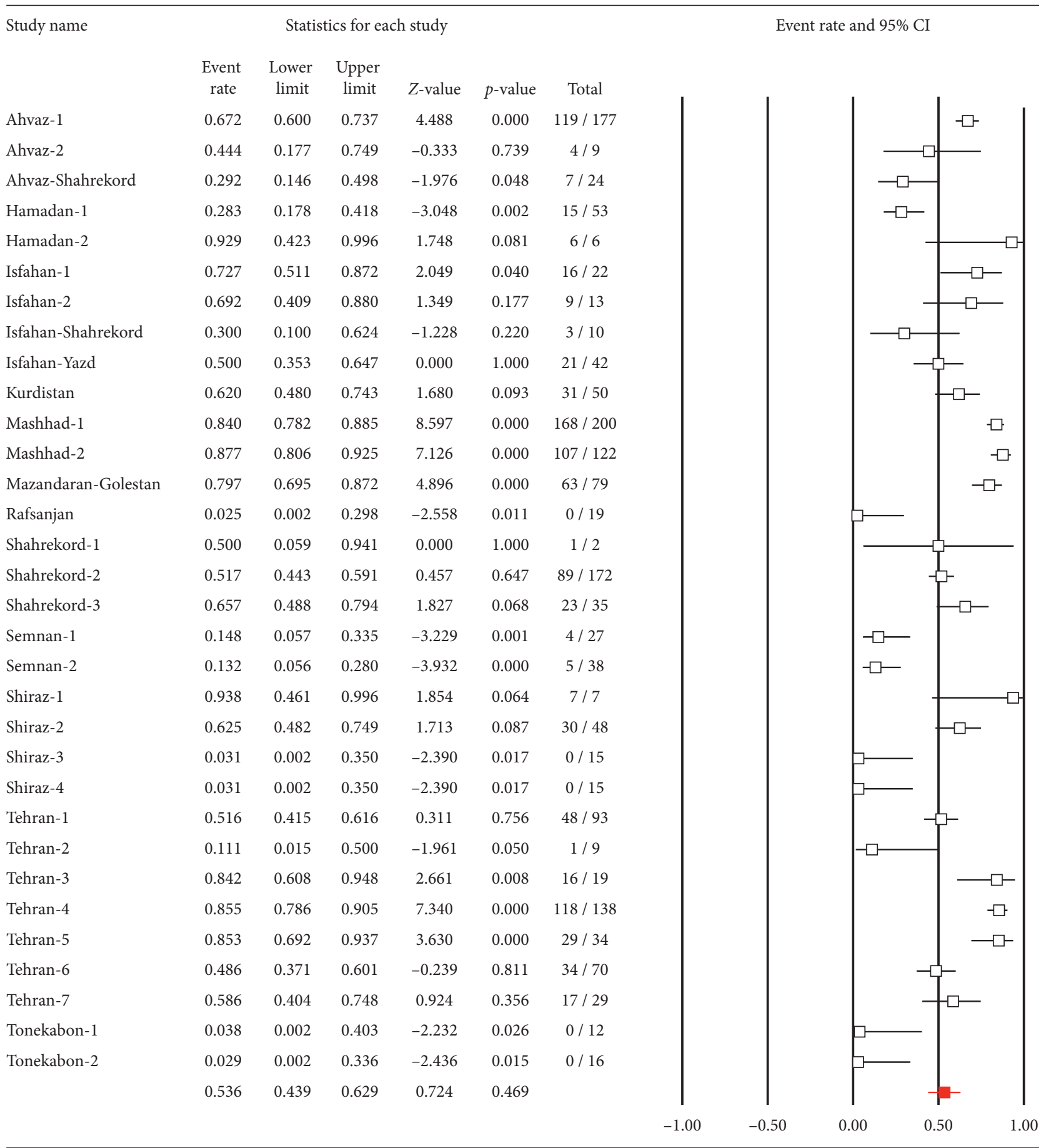

Figure 2: Funnel plot of the meta-analysis of the prevalence of $C$. jejuni resistant to ciprofloxacin in Iran.

Additionally, other antibiotic resistance patterns were as follows: ceftriaxone 7 (100\%), amikacin 0 (0\%), amoxi-clave 7 (100\%), penicillin $7(100 \%)$, vancomycin $7(100 \%)$ and tobramycin 2 (29\%).

Abbreviations: AMP: ampicillin; AMX: amoxicillin; CST: colistin; NFX: enrofloxacin; SPT: spectinomycin; NEO: neomycin; STR: streptomycin; CHL: chloramphenicol; TET: tetracycline; TMP/SMX: trimethoprim/sulfamethoxazole; CTX: cefotaxime; ERY: erythromycin; CIP: ciprofloxacin;
IPM: imipenem; GEN: gentamicin; MEM: meropenem; CEF: cephalothin; NAL: nalidixic acid; CAZ: ceftazidime; LEX: cephalexin; AST: antimicrobial susceptibility testing; ND: not determined.

\section{Discussion}

Food-borne illnesses caused by Campylobacter species as well as other bacteria related to food poisoning can be 


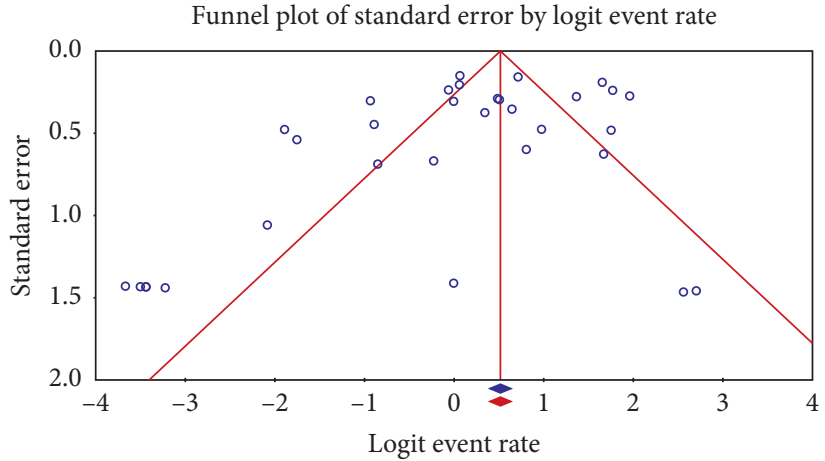

Figure 3: Funnel plot of the meta-analysis of the prevalence of C. coli resistant to ciprofloxacin in Iran.

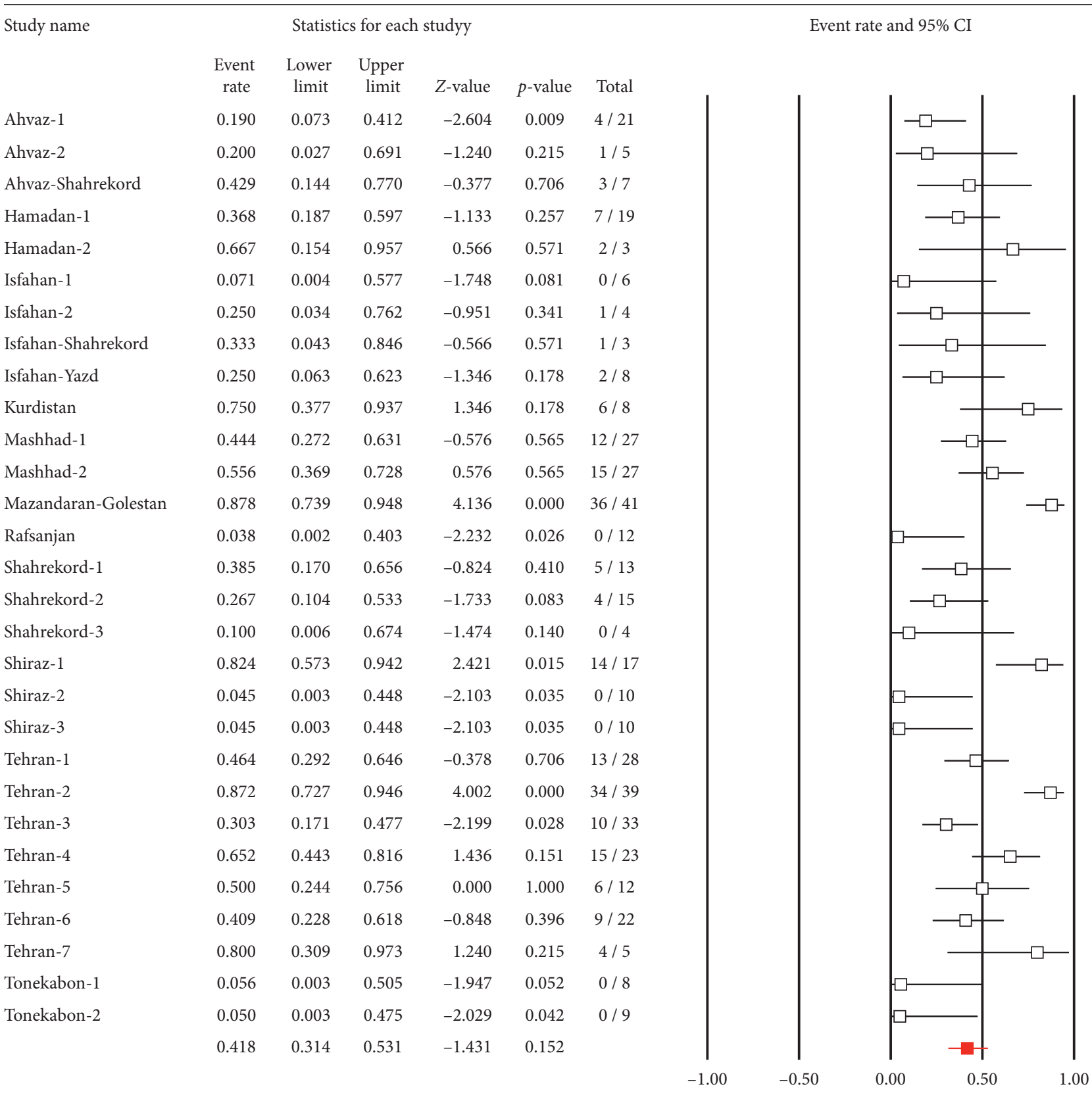




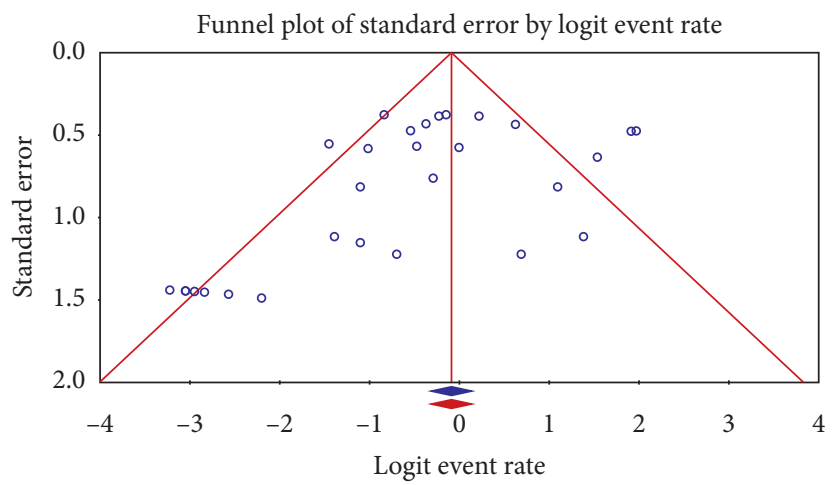

FIGURE 5: Forest plot of the meta-analysis of the prevalence of C. coli resistant to ciprofloxacin in Iran.

prevented by avoiding food contamination and growth of bacteria through proper food preparation and proper cooking as well as avoidance of contamination of water sources and consuming pasteurized dairy products [2, 45]. However, the main problem is food contamination with drug-resistant pathogens, which is a major threat to public health [46]. Antibiotic resistance genes can be transferred among food-borne pathogens, and this makes the treatment of severe infections difficult [46]. Today, fluoroquinoloneresistant Campylobacter species have turned into a global concern [9]. Fluoroquinolones are selective drugs in the treatment of campylobacteriosis; however, an increasing trend of resistance in Campylobacter species isolated from human and animal origins has been reported in the USA and Canada (19-47\%), European countries (17-99\%), and Africa and Asia (>80\%) [5]. According to the present study, the resistance of Campylobacter species isolated from human and animal origins to quinolones and fluoroquinolones including ciprofloxacin, nalidixic acid, enrofloxacin, and ofloxacin was also prevalent in Iran and varied from $0 \%$ to 87.3\% (Tables 1-3). Efflux pumps, CmeABC, and single point mutations in DNA gyrase A (GyrA) such as C257 T mutation, the most frequent mutation, are involved in chromosomally mediated quinolone resistance in Campylobacter species [5].

Macrolides are also recommended as another selective antibiotic class for the treatment of campylobacteriosis $[2,5]$. The resistance rate to erythromycin in Campylobacter species isolated from human and animal samples in Iran was low $(6.4 \%, 13 \%$, and $7.4 \%$ for C. jejuni, C. coli, and C. lari, respectively). The frequency of erythromycin resistance in Iran was higher than that in Turkey [47], Ethiopia [48], Canada [49], Australia [50], and the Czech Republic [51] and lower than that of South Africa [52], Malaysia [53], Italy [54], and China [55]. The target modifications through point mutations in the 23S rRNA gene such as A2074C, A2074G, and $\mathrm{A} 2075 \mathrm{G}$ mutations, modifying L4 and L22 ribosomal proteins along with CmeABC efflux pump, are three main mechanisms complicated in macrolide resistance in Campylobacter species [5].

Tetracyclines and gentamicin have also importance in Campylobacter infection therapy as second-line antibiotics $[2,4,5]$. The tet $(O)$ gene, which encodes a ribosomal protection protein, and $\mathrm{CmeABC}$ multidrug efflux pump are associated with tetracycline resistance in Campylobacter species [5]. Additionally, aminoglycoside-modifying enzymes play an important role in aminoglycoside resistance in Campylobacter species [5]. Based on the results of this study, C. jejuni and C. coli antibiotic resistance rates to tetracycline were much higher than gentamicin. Similar results were observed in the studies reported from Turkey [47], Italy [54], South Korea [56], and Poland [57]. Moreover, similar to our results, high rates of tetracycline resistance were reported in the studies of Turkey [47], Canada [49], South Africa [52], Malaysia [53], Italy [54], China [55], South Korea [56], and Poland [57]. Noteworthy, the determination of Campylobacter species susceptibility patterns against other antibiotics has received less attention. One reason could be attributed to the high sensitivity of bacteria to these antibiotics. For example, in the current study, antibiotic resistance pattern to protein synthesis inhibitors was low. On the other hand, resistance to protein synthesis inhibitors was lower than cell growth inhibitors and folic acid metabolism inhibitors.

As shown in other studies, the efficacy of cell growth inhibitor antibiotics against Campylobacter species is limited [5]. Our study also showed that among the three evaluated Campylobacter species, antibiotic resistance to $\beta$-lactam antibiotics, especially penicillins and cephalosporins, was high. On the other hand, the resistance rate to imipenem was lower than meropenem. The intrinsic resistance and $\beta$-lactamase enzymes are two main mechanisms of resistance to $\beta$-lactam antibiotics in Campylobacter species [5]. The intrinsic resistance is also the main resistance mechanism of Campylobacter species against vancomycin and folic acid metabolism inhibitors [5]. Our results confirmed high resistance rates to these antibiotics probably due to intrinsic resistance.

\section{Conclusion}

In accordance with the WHO report on fluoroquinoloneresistant Campylobacter species in the world and the urgent need to develop new antibiotics, our meta-analysis showed a high prevalence of resistance of Campylobacter species isolated from human and animal origins to quinolones and fluoroquinolones in Iran. On the other hand, compared to penicillins, cephalosporins, and sulfonamides, 
Campylobacter species were susceptible or showed low resistance rates to aminoglycosides, chloramphenicol, and imipenem. Therefore, these antibiotics could be recommended for the treatment of campylobacteriosis in Iran. We recommend monitoring antibiotic-resistant Campylobacter species through continuous drug sensitivity monitoring and investigating resistance mechanisms, especially against fluoroquinolones, to prevent further expansion of resistant species in Iran.

\section{Data Availability}

There are no original data associated with this review.

\section{Conflicts of Interest}

The authors declare that there are no conflicts of interest.

\section{References}

[1] K. C. Carroll, J. S. Butel, and S. A. Morse, Jawetz Melnick \& Adelbergs Medical Microbiology, McGraw Hill Professional, New York, NY, USA, 27th edition, 2016.

[2] P. R. Murray, K. S. Rosenthal, and M. A. Pfaller, Medical Microbiology, Elsevier Health Sciences, Amsterdam, Netherlands, 8th edition, 2015.

[3] T. Humphrey, S. O'Brien, and M. Madsen, "Campylobacters as zoonotic pathogens: a food production perspective," International Journal of Food Microbiology, vol. 117, no. 3, 237-257, 2007.

[4] K. Wieczorek and J. Osek, "Antimicrobial resistance mechanisms among Campylobacter," Biomed Research International, vol. 2013, Article ID 340605, 12 pages, 2013.

[5] T. Luangtongkum, B. Jeon, J. Han, P. Plummer, C. M. Logue, and Q. Zhang, "Antibiotic resistance in Campylobacter: emergence, transmission and persistence," Future Microbiology, vol. 4, no. 2, pp. 189-200, 2009.

[6] M. J. Blaser and J. Engberg, "Clinical aspects of Campylobacter jejuni and Campylobacter coli infections," Campylobacter, pp. 99-121, American Society for Microbiology (ASM),Washington, DC, USA, 3rd edition, 2008.

[7] J. Engberg, F. M. Aarestrup, D. E. Taylor, P. Gerner-Smidt, and I. Nachamkin, "Quinolone and macrolide resistance in Campylobacter jejuni and C. coli: resistance mechanisms and trends in human isolates," Emerging Infectious Diseases, vol. 7, no. 1, pp. 24-34, 2001.

[8] D. A. Alfredson and V. Korolik, "Antibiotic resistance and resistance mechanisms in Campylobacter jejuni and Campylobacter coli," FEMS Microbiology Letters, vol. 277, no. 2, pp. 123-132, 2007.

[9] World Health Organization, WHO Publishes List of Bacteria for which New Antibiotics are Urgently Needed, WHO, Geneva, Switzerland, 2017.

[10] A. Liberati, D. G. Altman, J. Tetzlaff et al., "The PRISMA statement for reporting systematic reviews and meta-analyses of studies that evaluate health care interventions: explanation and elaboration," PLoS Medicine, vol. 6, no. 7, Article ID e1000100, 2009.

[11] E. Rahimi, H. Momtaz, M. Ameri, H. Ghasemian-Safaei, and M. Ali-Kasemi, "Prevalence and antimicrobial resistance of Campylobacter species isolated from chicken carcasses during processing in Iran," Poultry Science, vol. 89, no. 5, pp. 1015-1020, 2010.
[12] A. D. Khosravi, M. Mehdinejad, A. Shamsizadeh, E. A. Montazeri, and M. Moghaddam, "Determination of antibiotic susceptibility pattern in Campylobacter jejuni and Campylobacter coli isolated from children with acute diarrhea," Asian Biomedicine, vol. 5, no. 5, pp. 611-618, 2011.

[13] E. Rahimi, M. Ameri, M. Alimoradi, A. Chakeri, and A. R. Bahrami, "Prevalence and antimicrobial resistance of Campylobacter jejuni and Campylobacter coli isolated from raw camel, beef, and water buffalo meat in Iran," Comparative Clinical Pathology, vol. 22, no. 3, pp. 467-473, 2013.

[14] A. Saadatmand, M. Y. Alikhani, R. Habibipour, and A. Heshmati, "Antibiotic resistance and prevalence of Campylobacter jejuni and Campylobacter coli in poultry liver," Scientific Journal of Hamdan University Medical Science, vol. 24, no. 3, pp. 252-258, 2017, in Persian.

[15] S. Rastyani, M. Y. Alikhani, I. Sedighi, S. Kazemi, H. F. Kohan, and M. R. Arabestani, "Campylobacter jejuni and Campylobacter coli in children with acute diarrhea in health centers of Hamadan, Iran," Avicenna Journal of Clinical Microbiology and Infection, vol. 2, no. 4, Article ID e29791, 2015.

[16] E. Rahimi, M. Alipoor-Amroabadi, and F. Khamesipour, "Investigation of prevalence of thermotolerant Campylobacter spp. in livestock feces," Canadian Journal of Animal Science, vol. 97, no. 2, pp. 207-213, 2017.

[17] A. Shakerian, E. Rahimi, and S. Kazemi, "Prevalence and antibiotic resistant of Campylobacter spp. isolated from different stages of sheep slaughterhouse," Food Health, vol. 1, no. 4, pp. 63-69, 2011, in Persian.

[18] E. Rahimi, S. Sepehri, and H. Momtaz, "Prevalence of Campylobacter species in milk and dairy products in Iran," Revue de Médecine Vétérinaire, vol. 164, no. 5, pp. 283-288, 2013.

[19] E. Rahimi, M. Ameri, and H. R. Kazemeini, "Prevalence and antimicrobial resistance of Campylobacter species isolated from raw camel, beef, lamb, and goat meat in Iran," Foodborne Pathogens and Disease, vol. 7, no. 4, pp. 443-447, 2010.

[20] A. S. Banuo and A. N. Saeide, "Isolation and survey for drug resistance of Campylobacter jejuni in poultry feces in Kerman," Iranian Journal of Medical Microbiology, vol. 9, no. 4, pp. 95-98, 2016, in Persian.

[21] K. Azizian, A. Hasani, S. Shahsavandi, M. Ahangarzadeh Rezaee, R. Hosseinpour, and H. Alizadeh, "Campylobacter jejuni and Campylobacter coli in cecum contents of chickens of slaughter age: a microbiological surveillance," Tropical Biomedicine, vol. 35, no. 2, pp. 423-433, 2018.

[22] B. Zendehbad, J. Khayatzadeh, and A. Alipour, "Prevalence, seasonality and antibiotic susceptibility of Campylobacter spp. isolates of retail broiler meat in Iran," Food Control, vol. 53, pp. 41-45, 2015.

[23] B. Zendehbad, A. A. Arian, and A. Alipour, "Identification and antimicrobial resistance of Campylobacter species isolated from poultry meat in Khorasan province, Iran," Food Control, vol. 32, no. 2, pp. 724-727, 2013.

[24] M. Raeisi, R. Khoshbakht, E. A Ghaemi et al., “Antimicrobial resistance and virulence-associated genes of Campylobacter spp. isolated from raw milk, fish, poultry, and red meat," Microbial Drug Resistance (Larchmont, N.Y.), vol. 23, no. 7, pp. 925-933, 2017.

[25] R. Shirzad-Aski, E. Rahim, and H. Mommtaz, "Investigation of morbidity and antibacterial resistance of Campylobacter spp. sample isolation from broilers slaughter in Rafsanjan city using basic culture method," Veterinary Researches and Biological Products, vol. 24, no. 2, pp. 53-58, 2011, in Persian. 
[26] A. Shakerian, "Campylobacter spp. as a potential pathogen in the edible mushrum (Agaricus mushrooms)," Journal of Food Microbiology, vol. 3, no. 1, pp. 63-72, 2016, in Persian.

[27] E. Rahimi and M. Ameri, "Antimicrobial resistance patterns of Campylobacter spp. isolated from raw chicken, Turkey, quail, partridge, and ostrich meat in Iran," Food Control, vol. 22, no. 8, pp. 1165-1170, 2011.

[28] E. Rahimi, A. Shakerian, H. R. Kazemeini, and M. A. Godarzi, "Antimicrobial resistance patterns of Campylobacter spp. isolated from raw chicken, Turkey, quail, partridge, ostrich, cow, sheep, goat and camel meat in Shahrekord," Food Technology Nutrition, vol. 10, no. 3, pp. 95-100, 2013, in Persian.

[29] A. Jazayeri Moghadas, G. Irajian, F. Kalantari et al., "Prevalence of Campylobacter jejuni in diarrheic children in Semnan (Iran)," Koomesh, vol. 9, no. 4, pp. 297-300, 2008, in Persian.

[30] G. Irajian, A. Jazayeri Moghadas, A. Beheshti, A. Salehian, M. Monem, and F. Moghaddas, "Prevalence of Campylobacter jejuni samples from patientsreferred to Semnan public health centers in 2007," Iranian Journal of Medical Microbiology, vol. 1, no. 4, pp. 35-39, 2008, in Persian.

[31] M. Aminshahidi, A. Arastehfar, G. Pouladfar, E. Arman, and F. Fani, "Diarrheagenic Escherichia coli and Shigella with high rate of extended-spectrum beta-lactamase production: two predominant etiological agents of acute diarrhea in Shiraz, Iran," Microbial Drug Resistance (Larchmont, N.Y.), vol. 23, no. 8, pp. 1037-1044, 2017.

[32] R. Khoshbakht, M. Tabatabaei, S. Hoseinzadeh, M. Raeisi, H. S. Aski, and E. Berizi, "Prevalence and antibiotic resistance profile of thermophilic Campylobacter spp. of slaughtered cattle and sheep in Shiraz, Iran," Veterinary Research Forum, vol. 7, no. 3, pp. 241-246, 2016.

[33] M. Baserisalehi, N. Bahador, and B. Kapadnis, "A comparison study on antimicrobial susceptibility of Campylobacter spp. isolates from faecal samples of domestic animals and poultry in India and Iran," Journal of Biological Science, vol. 7, no. 6, pp. 977-980, 2007.

[34] M. Ghane, N. Bahador, M. Baserisalehi, and M. Eghbali, "A comparative study on antimicrobial susceptibility of Campylobacter spp. isolates from fecal samples of domestic animals and poultry in Tonekabon and Shiraz, Iran," Journal of Paramedical Science, vol. 2, no. 2, pp. 21-26, 2011.

[35] H. Dabiri, S. Aghamohammad, H. Goudarzi, M. Noori, M. Ahmadi Hedayati, and S. M. Ghoreyshiamiri, "Prevalence and antibiotic susceptibility of Campylobacter species isolated from chicken and beef meat," International Journal of Enteric Pathogens, vol. 2, no. 2, pp. 1-4, 2014.

[36] M. Shirazi, Z. Vaise Malekshahi, D. Afshar, R. Ranjbar, and S. Hajikhani, "Drug resistance among Campylobacter jejuni strain isolated from children with diarrhea," Journal of Babol University of Medical Science, vol. 15, no. 1, pp. 79-83, 2013, in Persian.

[37] B. Bakhshi, M. Kalantar, A. Rastegar-Lari, and F. Fallah, "PFGE genotyping and molecular characterization of Campylobacter spp. isolated from chicken meat," Iranian Journal of Veterinary Research, vol. 17, no. 3, pp. 177-183, 2016.

[38] S. Mirzaie, M. Hassanzadeh, M. Bashashati, and A. Barrin, "Campylobacter occurrence and antimicrobial resistance in samples from ceca of commercial turkeys and quails in Tehran, Iran," International Research Journal of Microbiology, vol. 2, pp. 338-342, 2011.

[39] H. Jamali, A. Ghaderpour, B. Radmehr, K. S. C. Wei, L. C. Chai, and S. Ismail, "Prevalence and antimicrobial resistance of Campylobacter species isolates in ducks and geese," Food Control, vol. 50, pp. 328-330, 2015.

[40] M. Hamidian, M. Sanaei, M. Azimi-Rad, M. Tajbakhsh, H. Dabiri, and M.-R. Zali, "fla-typing, RAPD analysis, isolation rate and antimicrobial resistance profile of Campylobacter jejuni and Campylobacter coli of human origin collected from hospitals in Tehran, Iran," Annals Microbiology, vol. 61, no. 2, pp. 315-321, 2011.

[41] M. M. S. Dallal, M. P. Doyle, M. Rezadehbashi et al., "Prevalence and antimicrobial resistance profiles of Salmonella serotypes, Campylobacter and Yersinia spp. isolated from retail chicken and beef, Tehran, Iran," Food Control, vol. 21, no. 4, pp. 388-392, 2010.

[42] M. M. Feizabadi, S. Dolatabadi, and M. R. Zali, "Isolation and drug-resistant patterns of Campylobacter strains cultured from diarrheic children in Tehran," Japanese Journal of Infectious Disease, vol. 60, no. 4, pp. 217-219, 2007.

[43] M. Eghbali, M. Baserisalehi, and N. Bahador, "Antimicrobial susceptibility of thermophilic Campylobacter spp. isolated from environmental samples in Tonekabon," International Journal of Molecular and Cellular Medicine, vol. 1, pp. 21-24, 2011.

[44] M. Salehi, E. Shafaei, Z. Bameri et al., "Prevalence and antimicrobial resistance of Campylobacter jejuni," International Journal of Infection, vol. 1, no. 2, Article ID e19229, 2014.

[45] S. Jalalpour, "Food borne diseases bacteria; frequency antibiotic resistance bacteria in Iranian foods," African Journal Microbiology Research, vol. 6, no. 4, pp. 719-723, 2012.

[46] K. Enayat, A. Mansour, B. Nasrin, T. Mohammad, H. Mohammad, and N. Hanar, "Antibiotic resistance pattern in bacterial isolates obtained from frozen food samples of animal origin in Sanandaj and Ahvaz," African Journal of Bacteriology Research, vol. 4, no. 3, pp. 38-41, 2012.

[47] G. Ozbey and B. Tasdemi, "Seasonality and antibiotic resistance of Campylobacter in Turkish chicken meat," Veterinaria Italiana, vol. 50, no. 4, pp. 277-283, 2014.

[48] L. Dadi and D. Asrat, "Prevalence and antimicrobial susceptibility profiles of thermotolerant Campylobacter strains in retail raw meat products in Ethiopia," Ethiopian Journal of Health Development, vol. 22, no. 2, pp. 195-200, 2008.

[49] C. Narvaez-Bravo, E. N. Taboada, S. K. Mutschall, and M. Aslam, "Epidemiology of antimicrobial resistant Campylobacter spp. isolated from retail meats in Canada," International Journal of Food Microbiology, vol. 253, pp. 43-47, 2017.

[50] J. K. Miflin, J. M. Templeton, and P. J. Blackall, "Antibiotic resistance in Campylobacter jejuni and Campylobacter coli isolated from poultry in the South-East Queensland region," The Journal of Antimicrobial Chemotherapy, vol. 59, no. 4, pp. 775-778, 2007.

[51] J. Bardon, M. Kolar, L. Cekanova, P. Hejnar, and D. Koukalova, "Prevalence of Campylobacter jejuni and its resistance to antibiotics in poultry in the Czech Republic," Zoonoses and Public Health, vol. 56, no. 3, pp. 111-116, 2009.

[52] C. O. Shobo, L. A. Bester, S. Baijnath, A. M. Somboro, A. K. Peer, and S. Y. Essack, "Antibiotic resistance profiles of Campylobacter species in the South Africa private health care sector," Journal of Infection in Developing Countries, vol. 10, no. 11, pp. 1214-1221, 2016.

[53] J. M. Premarathne, A. S. Anuar, T. Y. Thung et al., "Prevalence and antibiotic resistance against tetracycline in Campylobacter jejuni and C. coli in cattle and beef meat from Selangor, Malaysia," Frontiers in Microbiology, vol. 8, Article ID 2254, 2017. 
[54] G. Pezzotti, A. Serafin, I. Luzzi, R. Mioni, M. Milan, and R. Perin, "Occurrence and resistance to antibiotics of Campylobacter jejuni and Campylobacter coli in animals and meat in northeastern Italy," International Journal of Food Microbiology, vol. 82, no. 3, pp. 281-287, 2003.

[55] X. Han, D. Zhu, H. Lai et al., "Prevalence, antimicrobial resistance profiling and genetic diversity of Campylobacter jejuni and Campylobacter coli isolated from broilers at slaughter in China," Food Control, vol. 69, pp. 160-170, 2016.

[56] B. Wei, S.-Y. Cha, M. Kang et al., "Antimicrobial susceptibility profiles and molecular typing of Campylobacter jejuni and Campylobacter coli isolated from ducks in South Korea," Applied and Environmental Microbiology, vol. 80, no. 24, pp. 7604-7610, 2014.

[57] E. Maćkiw, D. Korsak, K. Rzewuska, K. Tomczuk, and E. Rożynek, "Antibiotic resistance in Campylobacter jejuni and Campylobacter coli isolated from food in Poland," Food Control, vol. 23, no. 2, pp. 297-301, 2012. 